Article

\title{
Protection of Polyphenols against Glyco-Oxidative Stress: Involvement of Glyoxalase Pathway
}

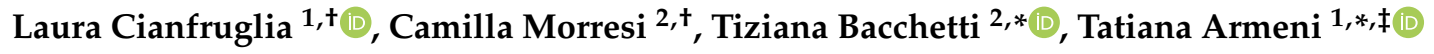 \\ and Gianna Ferretti ${ }^{1, \ddagger}$ \\ 1 Department of Clinical Sciences, Section of Biochemistry, Biology and Physics, \\ Polytechnic University of Marche, Via Brecce Bianche, 60131 Ancona, Italy; l.cianfruglia@univpm.it (L.C.); \\ g.ferretti@univpm.it (G.F.) \\ 2 Department of Life and Environmental Sciences, Polytechnic University of Marche, Via Brecce Bianche, \\ 60131 Ancona, Italy; c.morresi@univpm.it \\ * Correspondence: t.bacchetti@univpm.it (T.B.); t.armeni@univpm.it (T.A.) \\ + These authors share first authorship. \\ $\ddagger$ Research Center of Health Education and Promotion, Polytechnic University of Marche, Via Brecce Bianche, \\ 60131 Ancona, Italy.
}

Received: 14 September 2020; Accepted: 14 October 2020; Published: 16 October 2020

check for updates

\begin{abstract}
Chronic high glucose (HG) exposure increases methylglyoxal (MGO)-derived advanced glycation end-products (AGEs) and is involved in the onset of pathological conditions, such as diabetes, atherosclerosis and chronic-degenerative diseases. Under physiologic conditions the harmful effects of MGO are contrasted by glyoxalase system that is implicated in the detoxification of Reactive Carbonyl Species (RCS) and maintain the homeostasis of the redox environment of the cell. Polyphenols are the most abundant antioxidants in the diet and present various health benefits. Aims of the study were to investigate the effects of HG-chronic exposure on glyco-oxidation and glyoxalase system in intestinal cells, using CaCo-2 cells. Moreover, we studied the effect of apple polyphenols on glyco-oxidative stress. Our data demonstrated that HG-treatment triggers glyco-oxidation stress with a significant increase in intracellular Reactive Oxygen Species (ROS), lipid peroxidation, AGEs, and increase of Glyoxalase I (GlxI) activity. On the contrary, Glyoxalase II (GlxII) activity was lower in HG-treated cells. We demonstrate that apple polyphenols exert a protective effect against oxidative stress and dicarbonyl stress. The increase of total antioxidant capacity and glutathione (GSH) levels in HG-treated cells in the presence of apple polyphenols was associated with a decrease of GlxI activity.
\end{abstract}

Keywords: methylglyoxal; glyoxalase system; AGEs (advanced glycation end-products); glutathione; hyperglycemia

\section{Introduction}

Glyoxalase system is an important enzymatic system implicated in the detoxification of reactive carbonyl species (RCS) such as glyoxal (GO), methylglyoxal (MGO), and 3-deoxyglucosone (3-DG). In general, $\alpha$-oxoaldehydes are products of glycolytic metabolism and can be formed during lipid peroxidation, or glycation. The effects of $\mathrm{MGO}$, the most reactive metabolite, have been widely studied [1,2]. Accumulation of MGO to toxic level inhibits cell growth and induces cell death [3,4]. In fact, an abnormal accumulation of RCS triggers dicarbonyl stress, resulting in the formation of advanced glycation end-products (AGEs) and DNA modification. MGO can react also with other biomolecules such as nucleotides and basic phospholipids, thus yielding AGEs [5,6]. The increase in RCS contribute to cell and tissue dysfunction and is involved in ageing and in the molecular mechanisms of various chronic disease such as dyslipidemia, obesity, and vascular complications of diabetes $[7,8]$. 
Several studies have shown that the harmful effects of MGO are contrasted by glyoxalase system [9,10]. Glyoxalase system comprises two consecutive enzymes: glyoxalase I (GlxI) and glyoxalase II (GlxII). D-Lactate is a final product and glutathione (GSH) is used as cofactor [11]. Glyoxalase I (EC 4.4.1.5), a lactoylglutathione lyase, catalyzes the isomerization of the hemithioacetal formed non-enzymatically from MGO and reduced GSH to form S-D-lactoylglutathione. Glyoxalase II (EC 3.1.2.6), hydroxyacylglutathione hydrolase, catalyzes the hydrolysis of S-D-lactoylglutathione to D-lactic acid and restores the GSH molecule spent in the first reaction [12] (Figure 1).

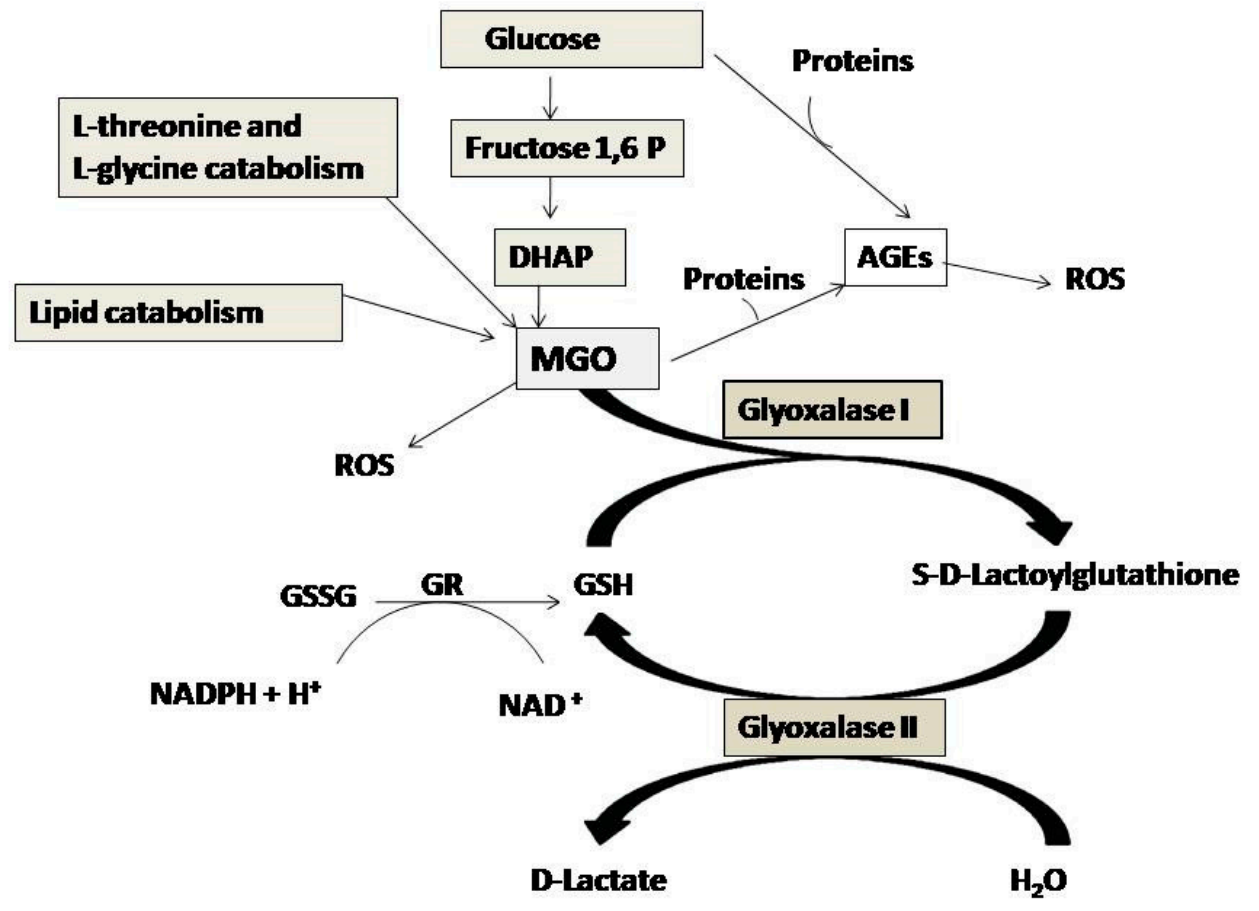

Figure 1. Methylglyoxal (MGO) formation from intermediates of glucose, protein and fat metabolism, and its degradation by the Glyoxalase System. Glyoxalase I (GlxI) converts hemithioacetal formed from glutathione (GSH) and methylglyoxal (MGO) into S-D-Lactoylglutathione (SLG) which is hydrolyzed by Glyoxalase II (GlxII) to D-lactic acid and GSH. Abbreviations: AGEs, advanced glycation end products; DHAP, dihydroxacetone phosphate; ROS, reactive oxygen species; GSH, reduced glutathione; GR, glutathione reductase.

Metabolic dysfunction involved in an increase of MGO, and consequently AGEs formation is associated with an increased Reactive Oxygen Species (ROS) formation [13]. Dicarbonyl stress can be increased by oxidative stress. In fact, oxidative stress can lead to a depletion of GSH thus compromising the pathway of glyoxalases that detoxify from MGO by using GSH [14]. Hyperglycemia, associated with diabetes, increased MGO and ROS formation. For instance, incubation of erythrocytes with high concentrations of glucose increases the formation of MGO metabolized to D-lactic acid by the glyoxalase pathway. This increase was proportional to glucose concentrations ranging from 5 to $100 \mathrm{mM}$ and it has been proposed that the glyoxalase system could be implicated in the progress of chronic clinical complications associated with diabetes mellitus [15,16].

Several studies have shown that glyoxalase system has a physio-pathological role in other chronic diseases. Indeed, it was shown that GlxI reduced dicarbonyl and oxidative stress and prevented age-related endothelial dysfunction, a major contributor to cardiovascular disease [17]. Dicarbonyl stress is a mediator that contributes to vascular complications and obesity diabetes-related and is involved in cerebrovascular diseases and neurological disorders $[18,19]$. Therefore, a growing interest is devoted to molecules able to decrease dicarbonyl stress targeting the glyoxalase system. Our recent study has shown that high glucose concentration triggers an increase of levels of intracellular 
ROS, lipid peroxidation, and formation of fluorescent AGEs and GA-modified proteins in intestinal cells [20].

Aims of the study were to investigate the effects of high glucose chronic exposure on glyco-oxidation and glyoxalase system in intestinal cells, using $\mathrm{CaCo}-2$ cells. Moreover, we studied the effect of apple polyphenols on glyco-oxidative stress. The $\mathrm{CaCo}-2$ cell line is an important tool in assessing various gastrointestinal functions and is widely used to investigate gastrointestinal oxidant metabolism on a cellular level [21]. In CaCo-2 cells, antioxidant enzymes include glutathione peroxidase, catalase, and paraoxonase-2 (PON2) [22]. Glyoxalase activities have not been studied until today in this cell model. The interest of the study is supported by the physiological relevance of GlxI and GlxII as protective enzymes against glyco-oxidative stress. In fact, intestinal cells are exposed to several diet pro-oxidant factors [23]. The effect of polyphenols on glyco-oxidative stress and glyoxalase has not been studied until today in intestinal cells. A growing interest is deserved to the study of the mechanisms involved in the protective effects exerted by diet polyphenols against glyco-oxidative stress [24,25]. In fact, epidemiological studies and randomized clinical trials have shown a strong association between consumption of polyphenols and reduced risk of several chronic diseases [26,27]. The protective role is exerted through different pathways and the ability to inhibit glycative stress and dicarbonyl stress has been studied in different experimental models as reviewed [28].

\section{Materials and Methods}

\subsection{Reagent}

Human colon epithelial cells CaCo-2 (ATCC ${ }^{\circledR} \mathrm{HTB}-37^{\mathrm{TM}}$ ) were obtained from the American Type Culture Collection (Rockville, MD, USA). The compounds for cell cultures were purchased by Euroclone (Euroclone, Italy). Carboxy- $\mathrm{H}_{2}$ DCFDA (C400) was supplied by Invitrogen (Invitrogen, Carlsbad, CA, USA). Goat polyclonal anti-AGE (AB9890) antibodies and rabbit polyclonal $\beta$-actin (A2066) were purchased by Sigma Aldrich (Sigma, St Louis, MO, USA). All other reagents have also been purchased from Sigma Aldrich (Sigma, St Louis, MO, USA).

\subsection{Polyphenolic Extract}

In this study, Calville White Winter apples were used. These apples are included in the Regional Repertory of Agro-biodiversity of Marche (Italy) managed by Agency for Agrofood Sector Services of the Marche Region (ASSAM, Marche Region, Italy). For preparation of the extract, apples were sliced thinly, the pits were removed, and the pulp was lyophilized in a Heto Dry Winner 685 (Denmark) lyophilizer for 4 days. Freeze dried samples were pounded through a laboratory mill and then kept at $-20{ }^{\circ} \mathrm{C}$. Apples lyophilized $(2 \mathrm{~g})$ were treated with $80 \%$ methanol and $0.1 \%$ formic acid in agreement with previous studies $[29,30]$. The hydro-alcoholic extract has been used for HPLC separation and quantification of phenolic compounds and our results have been previously published [30] and showed in Table 1.

To investigate the effect of apple polyphenols on cell-based assay, an aliquot of hydro-alcoholic extract has been used for solid-phase extraction (SPE) to remove polar non-phenolic compounds such as sugars and organic acids. CHROMABOND ${ }^{\circledR}$ PA C18 cartridges (Carlo Erba Reagents s.r.l, Cornaredo, Italy) were used to extract phenolic compounds acid from the apple extract based on the method described by Saeidi et al. [31]. Briefly, the SPE cartridge was sequentially conditioned with $5 \mathrm{~mL}$ of $\mathrm{n}$-hexane, $5 \mathrm{~mL}$ of methanol and $10 \mathrm{~mL}$ of double distilled deionized water without allowing the cartridge to dry. The filtrate was passed through the cartridge, washed by $8 \mathrm{~mL}$ water/methanol $(90: 10 v / v$, adjusted at $\mathrm{pH}=3$ with concentrated $\mathrm{HCl}$ ) to remove interferences and eluted with $4 \mathrm{~mL}$ HPLC grade methanol. Finally, the eluent (purified polyphenolic extract) was collected, concentrated using a rotary evaporator, dried, reconstituted with in sterile phosphate buffer saline (PBS). PBS-polyphenol extracts were stored under refrigeration $\left(-20^{\circ} \mathrm{C}\right)$ and used for cell incubation. Polyphenol yield of SPE has been evaluated as a balance between those initially found in hydro-alcoholic extract and those 
obtained in the retained and not retained fraction. Using Folin-Ciocalteu's method [32], the results demonstrated that polyphenols in purified polyphenolic extract accounted for about $72 \%$ of those in the hydroalcoholic extract.

Table 1. Polyphenolic compounds in Calville W.W. apple. Data are expressed as mean value (mg/100 g fresh weight) $(n=5)$.

\begin{tabular}{ccc}
\hline Class of Polyphenols & Polyphenolic Compound & $\begin{array}{c}\text { mg/100g FW (Fresh Weight) } \\
\text { Calville W.W. }\end{array}$ \\
\hline & procyanidin B1 & 5.78 \\
procyanidin B2 & 229.68 \\
Flavanols & procyanidin trimer & 88.74 \\
& procyanidin tetramer & 11.87 \\
& procyanidin pentamer & 5.25 \\
Flavones & epicatechin & 0.88 \\
Flavonols & Luteolin-glycoside & 2.37 \\
& Rutin + hyperin & 0.01 \\
& isoquercitrin & 3.13 \\
& reynoutrin & 0.018 \\
Hydroxycinnamic acids & guajaverin & 0.016 \\
Dihydrochalcones & avicularin & 0.011 \\
& chlorogenic acid & 0.027 \\
Anthocyanins & phloretin-2-o-xyloglucoside & 0.53 \\
Total polypjenols & phloridzin & 1.75 \\
& cyanidin-3-o-galactoside & 5.55 \\
& & 5.15 \\
\hline
\end{tabular}

\subsection{Cell Model and Apple Polyphenols Treatment}

CaCo-2 cells were cultured at $37^{\circ} \mathrm{C}$ in a humidified atmosphere containing $5 \%(v / v) \mathrm{CO}_{2}$. The culture medium was constituted by Dulbecco's minimal essential medium (DMEM) supplemented with $10 \mathrm{mM}$ nonessential ammino acids, 10\% (v/v) fetal bovine serum (FBS), $100 \mu \mathrm{g} / \mathrm{mL}$ streptomycin, $100 \mathrm{U} / \mathrm{mL}$ penicillin, $2 \mathrm{mM}$ glutamine. Cellular vitality was measured using Trypan Blue $0.1 \%$ exclusion assay. Cells were treated with culture medium containing $25 \mathrm{mM}$ (control cells) or $50 \mathrm{mM}$ glucose (high glucose, HG) concentrations for 1 week [20], in the absence or in the presence of apple extract containing two concentrations of polyphenols $(0.4 \mathrm{mmol} \mathrm{GAE} / \mathrm{L}$ and $0.8 \mathrm{mmolGAE} / \mathrm{L})$ [30,33]. Medium was replaced two times a week.

\subsection{Total Protein Quantification}

The cells were detached from the plate with trypsin and centrifuged at $1200 \times g$ for $10 \mathrm{~min}$. Pellets were rinsed twice with phosphate-buffered saline (PBS). The washed pellet was subsequently treated for $30 \mathrm{~min}$ on ice with a sodium-phosphate buffer $\mathrm{pH} 6.8$ containing protease inhibitors $(1.6 \mathrm{mM}$ aprotinin, $0.08 \mathrm{mM}$ bestatin, $2.08 \mathrm{mM}$ 4-(2-aminoeethyl) benzenesulfonil fluoride hydrochloride,

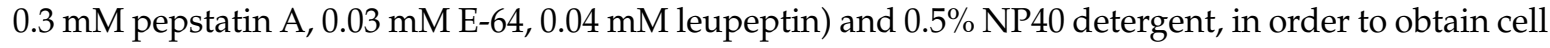
extracts. Cell lysates were subsequently centrifuged at $12,000 \times \mathrm{g}$ for $15 \mathrm{~min}$, at $4{ }^{\circ} \mathrm{C}$. Supernatants were recovered and total protein concentration was measured by the Bradford assay.

\subsection{Advanced Glycation End Products (AGEs)}

Fluorescent AGE levels were measured by reading the intrinsic fluorescence of AGE at $340 \mathrm{~nm} / 420 \mathrm{~nm}$ (excitation and emission wavelengths respectively) on a microplate reader (Synergy microplate reader, BioTek Instruments, Inc.). The data are the result of the fluorescence intensity per mg of cell proteins [34]. 
For detection of total glycolaldehyde (GA)-modified proteins, Western blot analysis was performed. Cells extracts, containing $50 \mu \mathrm{g}$ of protein, were run on $12.5 \%$ SDS-PAGE and then transferred to a polyvinylidene fluoride (PVDF) membrane. After blocking and washing, the membranes were incubated overnight with anti-AGE polyclonal goat (\#AB9890 Merk Millipore, Burlington, MA, USA) at $4{ }^{\circ} \mathrm{C}$. $\beta$-actin (A2066 Sigma-Aldrich, St. Louis, MO, USA) has been used as loading control. The membranes were then incubated with HRP-labeled secondary specific antibodies (A50-101P Dako, Santa Clara, CA, USA) for $1.30 \mathrm{~h}$ after being washed three times with Tris-buffered containing 0.1\% Tween 20 (TBST). SuperSignal West Femto Maximum Sensitivity Substrate (Thermo Fisher Scientific, Waltham, MA, USA) was used for band development while the ChemiDoc XRS+System (Bio-Rad Laboratories, Hercules, CA, USA) were used to detect chemoluminescence. The chemiluminescent signal was analyzed by Image J software (Version 1.50i, National Institute of Health, Bethesda, MD, USA).

\subsection{Intracellular ROS Levels}

The intracellular ROS levels were evaluated using the probe carboxy-2,7-dichlorofluorescein diacetate (carboxy- $\mathrm{H}_{2} \mathrm{DCFDA}$ ) (Invitrogen, Carlsbad, CA, USA) and detected by flow cytometry. The cells, resuspended at a final concentration of $0.5 \times 10^{6} \mathrm{cells} / \mathrm{mL}$, were incubated at $37^{\circ} \mathrm{C}$ in preheated PBS containing $10 \mu \mathrm{M}$ carboxy- $\mathrm{H}_{2}$ DCFDA for $30 \mathrm{~min}$ in the dark. The cells were washed twice in PBS and then stained with $10 \mu \mathrm{g} / \mathrm{mL}$ propidium iodide (PI). The fluorescence of the cells was detected by cytofluorimetric analysis (Coulter EPICS XL, Beckman Coulter, CA USA), using an excitation wavelength of $488 \mathrm{~nm}$. To assess ROS levels only on viable cells, cells that had absorbed PI and therefore had compromised cell permeability, were excluded from the analysis. The data were subsequently analyzed by the FCS Express Program (De Novo Software, CA, USA).

\subsection{Lipid Peroxidation Products}

The levels of malondialdehyde (MDA), the major lipid peroxidation products were evaluated as thiobarbituric acid reactive substances (TBARS) [35]. Briefly, one $\mathrm{mL}$ of $20 \%(w / v)$ trichloroacetic acid containing $0.8 \%(w / v)$ thiobarbituric acid (TBA) was added to each culture dish (60 mm diameter). The cells were scratched off and transferred to glass centrifuge tubes. After incubation at $95{ }^{\circ} \mathrm{C}$ for $45 \mathrm{~min}$ samples were cooled to room temperature in an ice bath for $10 \mathrm{~min}$. All samples were centrifugated and the absorbance of the supernatant was evaluated on a microplate reader at OD $535 \mathrm{~nm}$. The molar extinction coefficient of the (Malondialdehyde) MDA-TBA complex of $1.49 \times 10^{5} \mathrm{M}^{-1} \mathrm{~cm}^{-1}$ was used to calculate the amount of TBARS. Results are expressed as nmol MDA equivalents formed per mg protein.

\subsection{Cell total Antioxidant Capacity}

The total antioxidant capacity of $\mathrm{CaCo}-2$ cells incubated in different experimental conditions was performed by Oxygen radical absorbance capacity (ORAC) assay. Briefly, Trolox standard and samples were added to wells in a black 96-well microplate. A volume of Fluorescein solution was added to each well (final concentration $0.08 \mathrm{mM}$ ) and incubated at $37{ }^{\circ} \mathrm{C}$ for $20 \mathrm{~min}$ before the addition of $17.5 \mathrm{mM}$ freshly prepared 2,2'-Azobis(2-methylpropionamidine) dihydrochloride (AAPH) in working buffer. The decay of fluorescence at $530 \mathrm{~nm}$ was evaluated for $3 \mathrm{~h}$ in a microplate reader (BioTek Synergy HP, VT, USA) with excitation wavelength at $485 \mathrm{~nm}$. The area under the fluorescence versus time curve was used for quantification [36]. Antioxidant capacity was expressed as mmol Trolox equivalents (TE) $/ 10^{6}$ cells.

\subsection{Quantitative Determination of Total Glutathione}

The glutathione reductase (GR) recycling assay in the presence of 5,5-dithiobis (2-nitrobenzoic acid) (DTNB) was used to evaluate total levels of glutathione at $412 \mathrm{~nm}$. A solution of GSH was used for the calibration curve [37]. Cells were trypsinized, washed twice in cold PBS, and centrifuged. Then the 
pellet was resuspended with $1 \%$ sulfosalicylic acid. All samples were incubated 30 min at $4{ }^{\circ} \mathrm{C}$ and after centrifugation at $2300 \times g$ for $2 \mathrm{~min}$, the supernatant was recovered and analyzed for glutathione quantification. Finally, the pellet was resuspended with $1 \mathrm{M} \mathrm{NaOH}$ for recovery and used to quantify proteins using the Bradford method. Intracellular total glutathione is expressed as nmol/mg protein.

\subsection{Glyoxalase System Enzymatic Assay}

Glyoxalase I activity was determined spectrophotometrically at $25{ }^{\circ} \mathrm{C}$ by monitoring the intermediate S-D-lactoylglutathione (SLG) formation at $240 \mathrm{~nm}$ for $1 \min \left(\varepsilon=2.86 \mathrm{mM}^{-1} \mathrm{~cm}^{-1}\right)$. The hemithioacetal is pre-formed in situ by incubation of $2 \mathrm{mM} \mathrm{GSH}$ (freshly prepared) and $2 \mathrm{mM}$ MGO in $100 \mathrm{mM}$ phosphate-buffer $\mathrm{pH}$ 6.8. Samples were incubated at room temperature in the dark for $15 \mathrm{~min}$. Then, $50 \mu \mathrm{L}$ of each sample were used. GlxI activity was expressed as $\mu \mathrm{mol} / \mathrm{min} / \mathrm{mg}$ protein [38].

To evaluate Glyoxalase II activity, the increase of GSH was studied for 1 min at $412 \mathrm{~nm}$ $\left(\varepsilon=13.6 \mathrm{mM}^{-1} \mathrm{~cm}^{-1}\right)$. Briefly, samples were incubated in the reaction mixture containing $100 \mathrm{mM}$

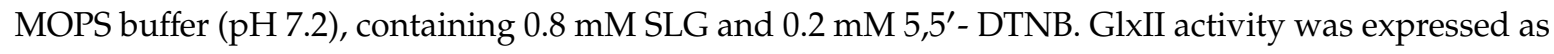
$\mu \mathrm{mol} / \mathrm{min} / \mathrm{mg}$ protein [39].

\subsection{Statistical Analysis}

Data are expressed as the mean of measurements conducted separately \pm Standard deviation. The Tukey-Kramer multiple comparison test or Kruskal-Wallis 1-way ANOVA were used to determine significant differences between treated and control cells.

\section{Results}

\subsection{Effect of High Glucose and Polyphenols on Oxidative Stress}

Table 1 summarizes polyphenol composition evaluated previously by HPLC analysis [30]; the hydroalcholicextract obtained from Calville White Winter apples was mainly composed of flavonols, in particular procyanidins, anthocyanins, and dihydrochalcones (phloridzin and phloretin-2-o-xyloglucoside) (Table 1).

As shown in Table 2, we observed a significant increase in intracellular ROS and a significant decrease of total intracellular antioxidant capacity in cells incubated with HG compared with control cells. There was also an increase in MDA expressed as TBARS $(p<0.001)$. All these results support that our experimental conditions trigger glyco-oxidative stress of $\mathrm{CaCo}-2$ cells.

Table 2. The oxidative stress in HG-treated CaCo-2 cells with or without polyphenols extract. Intracellular ROS production, total antioxidant capacity, lipid peroxidation, and total AGEs levels in control cells ( $25 \mathrm{mM}$ glucose, Ctrl) or high glucose treated cells (50 mM glucose) incubated in the absence (HG) or in the presence of apple polyphenolic extract ( 0.4 and $0.8 \mathrm{mmol} \mathrm{GAE} / \mathrm{L})$. Results are represented as mean \pm SD of 5 determinations carried out in triplicate. Different letters a-d indicate significant statistic differences between samples $(p<0.05)$.

\begin{tabular}{cccc}
\hline & $\begin{array}{c}\text { Intracellular ROS Production } \\
\text { (Intensity of Fluorescence A.U.) }\end{array}$ & $\begin{array}{c}\text { Antioxidant Capacity } \\
\left(\boldsymbol{\mu m o l ~ T E / 1 0 ^ { 6 }} \text { Cells) }\right.\end{array}$ & $\begin{array}{c}\text { Lipid Peroxidation } \\
\text { (nmol/mg Protein) }\end{array}$ \\
\hline CTRL & $14 \pm 2^{\mathrm{a}}$ & $806 \pm 161^{\mathrm{a}}$ & $0.55 \pm 0.21^{\mathrm{a}}$ \\
$\mathrm{HG}$ & $29 \pm 2^{\mathrm{b}}$ & $286 \pm 152^{\mathrm{b}}$ & $3.01 \pm 0.62^{\mathrm{b}}$ \\
$\mathrm{HG}+$ Extract & $15 \pm 1^{\mathrm{a}}$ & $592 \pm 150^{\mathrm{c}}$ & $0.92 \pm 0.18^{\mathrm{c}}$ \\
$\begin{array}{c}\text { (n mmol GAE/L } \\
\mathrm{HG}+\text { Extract }\end{array}$ & $10 \pm 1^{\mathrm{c}}$ & $715 \pm 157^{\mathrm{d}}$ & $0.54 \pm 0.08^{\mathrm{a}}$ \\
$0.8 \mathrm{mmol} \mathrm{GAE} / \mathrm{L}$ & & & \\
\hline
\end{tabular}

In cells incubated in the presence of high glucose and apple polyphenol extract $(0.4$ and $0.8 \mathrm{mmol}$ $\mathrm{GAE} / \mathrm{L}$ ) significant differences were observed. Lower levels of intracellular ROS and lipid peroxidation 
were observed, moreover, total antioxidant capacity was increased (Table 2). The protective effect was related to polyphenol concentration. These results demonstrate that polyphenol treatment protects CaCo-2 cells against oxidative stress.

\subsection{Effect of High Glucose and Polyphenols on AGEs Formation}

As shown in Figure 2, a significant increase in fluorescent AGEs formation and GA-modified proteins in cells incubated with HG compared with control cells was observed. HG plus polyphenolic extract treatment decreased significantly AGEs formation with respect to HG-treated cells. The effect on fluorescent AGEs was dependent on polyphenol concentration (Figure 2).

A

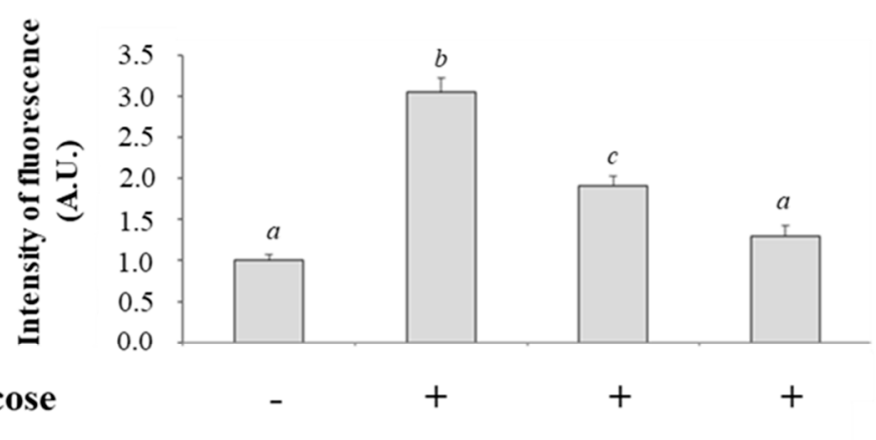

Extract 0.4mmol GAE/L

Extract $0.8 \mathrm{mmol}$ GAE/L

B

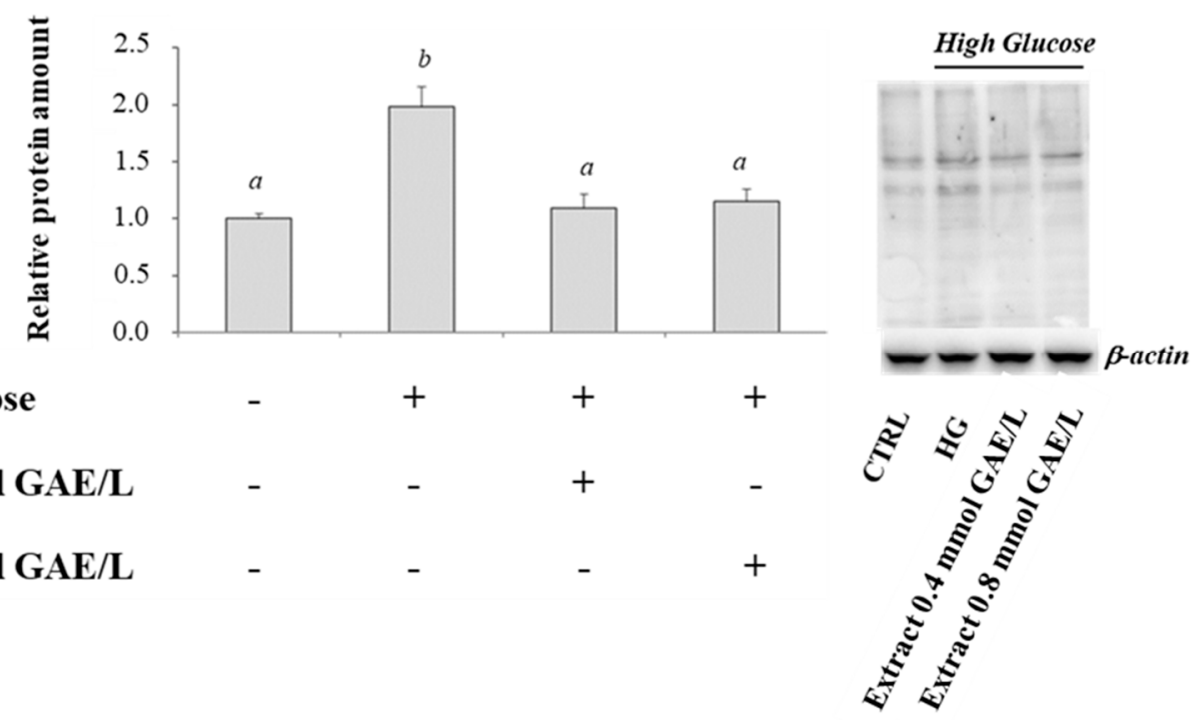

Figure 2. AGEs formation and GA-modified protein in HG-treated CaCo-2 cells in absence and in the presence of apple polyphenolic extract. (A) Levels of total fluorescent AGEs and (B) Representative western blot of GA-modified proteins and relative densitometric analysis, in control cells ( $25 \mathrm{mM}$ glucose, Ctrl) or high glucose treated cells (50mM glucose) incubated in the absence (HG) or in the presence of apple polyphenolic extract $(0.4$ and $0.8 \mathrm{mmol} \mathrm{GAE} / \mathrm{L})$. Densitometric data are normalized on $\beta$-actin. Results are presented as mean \pm SD of 5 determinations carried out in triplicate. Different letters a-c indicate significant statistic differences between samples $(p<0.05)$. 


\subsection{Effect of High Glucose and Polyphenols on Glyoxalase System}

We studied the effects of incubation of cells with HG on glyoxalase system. Therefore, we compared the activities of GlxI and GlxII and levels of total glutathione in control cells and cells incubated with HG. GlxI activity increased significantly after HG treatment compared with control cells (Figure 3A), while GlxII activity was lower in HG-treated cells (Figure 3B). GSH levels were not significantly modified (Figure 4).

A

GlxI Activity

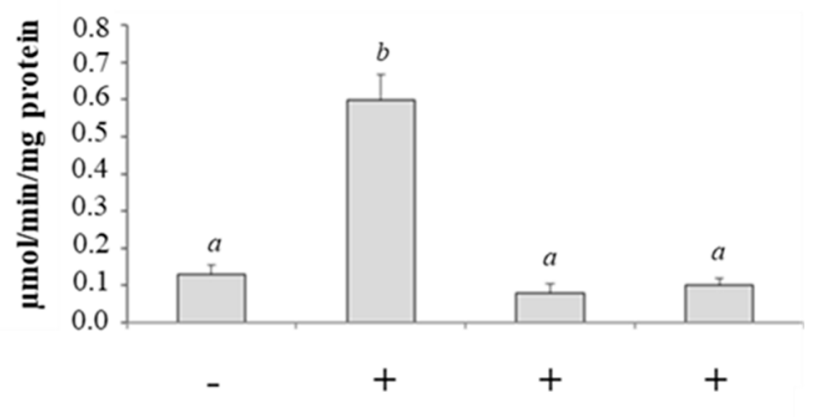

Extract $0.4 \mathrm{mmol}$ GAE/L

Extract $0.8 \mathrm{mmol}$ GAE/L

B

GlxII Activity

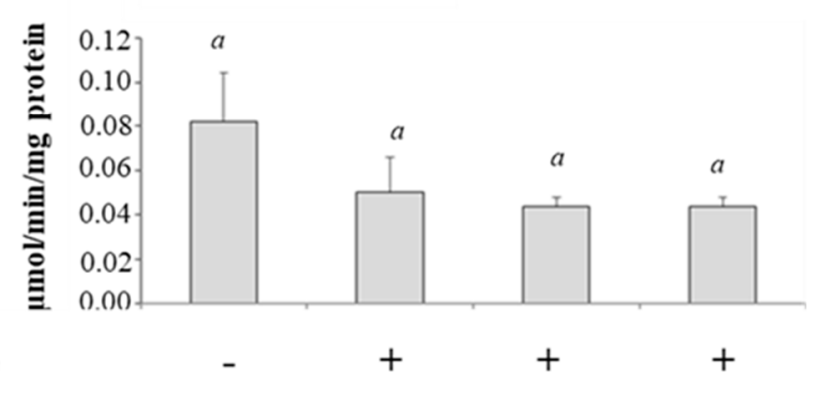

\section{Extract $0.4 \mathrm{mmol}$ GAE/L}

\section{Extract $0.8 \mathrm{mmol}$ GAE/L}

Figure 3. The glyoxalase system in HG-treated CaCo-2 cells incubated in the absence or in the presence of apple polyphenolic extract. (A) Glx I and (B) Glx II activity in intestinal CaCo-2 cells treated for one week with normal $(25 \mathrm{mM})(\mathrm{Ctrl})$, or with high glucose $(50 \mathrm{mM})$ concentrations in the absence (HG) or in the presence of polyphenolic extract $(0.4$ and $0.8 \mathrm{mmol}$ GAE/L). Results are presented as mean $\pm \mathrm{SD}$ of 5 determinations carried out in triplicate. Different letters a,b indicate significant statistic differences between samples $(p<0.05)$. 


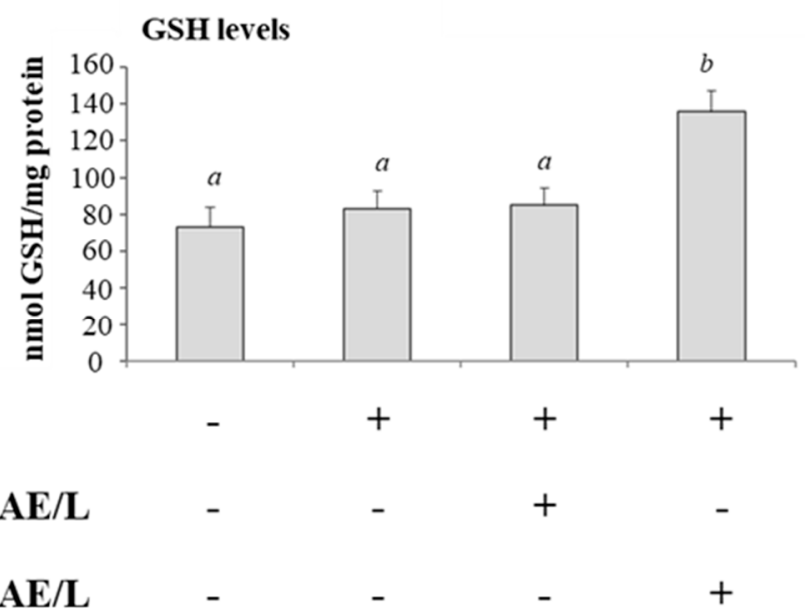

Figure 4. Glutathione level in HG-treated CaCo-2 cells in the absence or in the presence of apple polyphenolic extract Glutathione (GSH) level in control cells ( $25 \mathrm{mM}$ glucose, Ctrl) or high glucose treated cells (50 mM glucose) incubated in the absence (HG) or in the presence of apple polyphenolic extract $(0.4$ and $0.8 \mathrm{mmol} \mathrm{GAE} / \mathrm{L})$. Results are represented as mean $\pm \mathrm{SD}$ of 5 determinations carried out in triplicate. Different letters a,b indicate significant differences between samples $(p<0.05)$.

GlxI activity was lower in HG-treated cells incubated with polyphenolic extract and the activity was getting closer to control cells (Figure 3A); GlxII was not significantly modified after incubation with polyphenols (Figure 3B). Intracellular levels of GSH were increased in HG-treated cells incubated with polyphenols; the effect was significant at the higher concentration of polyphenols (Figure 4).

\section{Discussion}

Many "in vivo" and "in vitro" studies have shown that there is a strong correlation between a hyperglycemia condition and the formation of AGEs [40,41]. As previously demonstrated, intestinal cells are sensitive to glyco-oxidative stress when exposed to high glucose concentrations [20]. Glyco-oxidative stress was confirmed in this study with an increase of AGEs formation, increase of intracellular ROS production, lipid peroxidation, and a decrease of total antioxidant capacity.

Glyoxalase system plays a key role against dycarbonyl stress as it maintains MGO at levels that are non-toxic to the cell. The glyoxalases system has always been studied as a pathway of MGO detoxification in a unique way, while in recent years some studies have considered the role of glyoxalases in the cellular redox signalling. The two enzymes involved (GlxI and GlxII) use GSH as a cofactor whose concentration must be considered as a factor closely related to the efficiency of the system itself. So, the increase in the MGO concentration and AGE, within the cell, may be due not only to increasing with high rates of glycolysis, but also to a decreased availability of GSH used under ROS overproduction condition. In light of this, the enzymatic activity of glyoxalases may be important in the cellular response to glyco-oxidative stress.

In our experimental model, under HG conditions, we observed a marked increase in GlxI activity coupled with a constant level of glutathione in comparison to the control. The high activity of the GlxI implies consumption of GSH which is however maintained at constant levels. Since GSH is a fundamental component in redox homeostasis, it is possible to assume that the cell must necessarily restore, as soon as possible, the amount consumed of GSH especially in conditions of chronic stress as in our experimental model. An increase in GlxI activity has been observed by other authors in HG treated cells and it has been suggested as a possible protection from high MGO formation in HG condition [42].

In our experimental conditions, despite the significant increase in GlxI activity, levels of AGEs were higher in HG treated cells. Other authors have demonstrated that the GlxI enzyme was ineffective 
to normalize MGO [43] in HG-treated cells. It has also to be stressed that AGEs formation does not only occur due to the increase of intracellular MGO but also as a consequence of glucose auto-oxidation and the non-enzymatic Maillard reaction and/or lipid peroxidation.

Contrasting results have been reported on the effects of incubation with high glucose levels on glyoxalase system in different experimental models. In vivo studies in streptozotocin induced diabetic rat, an increase in GlxI and GlxII activity in red blood cells and skeletal muscle was observed while the activity decreased in the liver $[44,45]$. Other authors have demonstrated that GlxI increased in glomeruli of diabetic mice, while decreased in renal cortex [46]. A decrease of GlxI activity has been shown in SH-SY5Y neuroblastoma cells, and on human brain microvascular endothelial cell line (IHEC) during hyperglycemia. Furthermore, the effects of high glucose on GLxI and GLxII differ. For instance, no effects on GlxII activity have been observed [47]. All these findings suggest that the effects of high glucose concentrations on glyoxalase enzymes are strongly tissue specific.

Moreover, the activity of GlxII is about 10-fold lower than that of GlxI so it is the rate limiting enzyme of the MGO pathway [8]. GlxII is found in two isoforms, cytosolic and mitochondrial, which are differently regulated. The study by Scirè et al. [48] shows that acid phospholipids inhibit only the cytosolic form of GlxII and not the mitochondrial one, thus assuming a regulatory role of GlxII enzyme. It has also been shown that S-D-lactoylglutathione, when it accumulates in the cytoplasm, can enter into the mitochondria where it is used by mitochondrial GlxII [49]. Therefore, GlxII can represent a regulatory step of the glyoxalase pathway and for this reason the activity levels of GlxII do not always have the same trend as those of GLxI. Moreover, protein-protein interaction studies, performed using a validated in silico approach [50], have been shown that GlxII could catalyze protein S-glutathionylation using S-D-lactoylglutathione as substrate, on specific redox dependent proteins [39]. This capacity implies that S-D-lactoylglutathione formation from MGO and GlxII activity could play a relevant role in the regulation of cell metabolism and redox signaling.

In our experimental conditions, incubation with polyphenols during HG treatment was associated with a decrease of AGEs formation, ROS production, and lipid peroxidation evaluated as TBARS. Furthermore, an increase of total antioxidant capacity and GSH levels was observed. All these results demonstrate that apple polyphenols were able to counteract the glyco-oxidation induced by HG. Other studies have demonstrated the ability of fruit polyphenols to exert a protective effect against formation of AGEs [28,30,51,52]. There are many steps in ROS and AGEs production therefore different mechanisms may occur to delay or decrease intracellular ROS and AGEs formation [28,51]. Purified phenolic compounds can reduce glyco-oxidative stress through many pathways, including reduction of ROS production during the glycation process and trapping of dicarbonyl species [28,51]. A large amount of ROS is produced by the early stage of the Maillard reaction and Schiff bases produce ROS and RCS. Therefore, capturing ROS at the early stage of glycation can inhibit glycation. Moreover, polyphenolic compounds with specific chemical structural arrangement exert a high reactivity with MGO [53,54]. An MGO-trapping effect of some apple polyphenols (quercetin, phloretin and phloridzin) has been recently demonstrated [28,55].

In our study, the significant decrease of ROS formation and increase in GSH levels in cells treated with apple polyphenols during incubation with high glucose levels, was associated with a decrease of GlxI activity at values similar to those observed in control cells. In this picture it is possible to hypothesize a lower need to transform the MGO and this event can be correlated with the direct trapping activity of polyphenols on the MGO.

Other studies have reported conflicting results. Frandsen et al. [56] demonstrated that the flavonoids catechin, morin, and quercetin enhanced the glyoxalase pathway in neuronal cells in culture with an over-expression of GlxI, GlxII, increase of GSH and decrease the concentration of ROS. While other studies show that polyphenols such as curcumin, luteolin, myricetin, and kaempferol negatively modulate GlxI [57-59].

Different mechanisms could be advanced to explain the effect of apple polyphenols on GSH levels and glyoxalases in CaCo-2 cells exposed to high glucose levels. It has been suggested that 
modulating signaling pathways involved in cellular behavior, GSH synthesis, and expression of antioxidant enzymes could be involved as suggested by other authors [56]. In the glyoxalase pathway, GSH is involved, as cofactor, in the first reaction that converts MGO to D-lactate. In some cell models, an increase of intracellular concentration of GSH, modulates glyoxalase pathway. Apple contains several flavonoids as demonstrated in our study. Some authors have suggested that the increase in GSH levels in flavonoid treated cells could be related to transactivation of catalytical subunit promoter of the gamma-glutamyl-cysteine synthetase [60]. GSH is involved in cellular redox regulation as it can be used as a cofactor by enzymes involved in signal transduction [61,62], therefore our results suggest that polyphenol-mediated regulation of GSH levels could modulate cellular response in intestinal cells. Moreover, some flavonoids behave as natural inhibitors of GlxI [63].

We confirm that apple polyphenols exert a protective effect against oxidative stress and dicarbonyl stress in CaCo-2 cells. The effect was observed at concentrations ranging $4-8 \times 10^{-4} \mathrm{~mol} / \mathrm{L}$. Polyphenols are the most abundant antioxidants in the diet [64]. It has been reported that bioavailability of polyphenols is related to structural properties of molecules. Total levels of polyphenolic compound are present in plasma at $<1 \mu \mathrm{mol} / \mathrm{L}$ concentrations, but they are present in the stomach and intestinal lumen at much higher concentrations after consumption of foods and beverages rich in such compounds. For example, the dilution of $500 \mathrm{mg}$ of polyphenols with the digestive bolus in the colon would give a local concentration of about $3 \mathrm{mM}$ [65]. The poor intestinal absorption is responsible for luminal concentrations of phenolic compounds up to several hundred $\mu$ mols in the gastrointestinal tract [66].

Previous studies have shown that incubation of intestinal cells with apple extracts results in a marked increase in intracellular concentration of some polyphenols such as catechin, caffeic acid, and epicatechin indicating that these compounds are able to penetrate cell membranes [33]. In addition, a number of phenolic compounds and their conjugates have been detected and identified in $\mathrm{CaCo}-2$ cell lysates, confirming their active uptake and metabolism [67]. Further studies are necessary to investigate whether the effects of polyphenols on glyco-oxidative stress of $\mathrm{CaCo} 2$ cells are exerted by metabolites of apple polyphenols. In fact, the main metabolites of polyphenols have become the subject of manifold research studies and several bioactive roles have been demonstrated [68].

\section{Conclusions}

In conclusion in this work it has been highlighted that the MGO detoxification system is closely related to the redox balance of the cell even under conditions of glyco-oxidative stress. In particular, changes in the enzymes activity of the glyoxalase system may suggest an involvement of this metabolic pathway in the antioxidant cellular response.

The incubation with polyphenols during HG treatment is associated with the recovery of glyco-oxidative stress parameters demonstrating that apple polyphenolic extracts were able to counteract the glyco-oxidation, even with the involvement of the glyoxalase system. Therefore, the polyphenols contained in apples can have two beneficial properties for the cell. On the one hand they increase the antioxidant capacity and therefore predispose the cell to an advantageous condition to deal with chronic stress, on the other hand they work directly from antioxidants and trapping for harmful compounds such as MGO. Further studies are necessary to understand better the effects of high glucose and polyphenols on dicarbonyl stress and glyoxalase system in intestinal cells and the molecular mechanisms that could be involved.

Author Contributions: Conceptualization, G.F., T.A. and T.B.; methodology, L.C. and C.M.; validation, G.F., T.A. and T.B.; formal analysis, L.C. and C.M.; investigation, L.C. and C.M.; resources, L.C. and C.M.; data curation, G.F., T.A. and T.B.; writing-original draft preparation, L.C. and C.M.; writing-review and editing, G.F., T.A. and T.B.; visualization, G.F., T.A. and T.B.; supervision, G.F., T.A. and T.B.; project administration, G.F. funding acquisition, G.F., T.A. and T.B. All authors have read and agreed to the published version of the manuscript.

Funding: This research was funded by Polytechnic University of Marche (Project number: RSA498).

Conflicts of Interest: The authors declare no conflict of interest. 


\section{References}

1. Phillips, S.A.; Thornalley, P.J. The formation of methylglyoxal from triose phosphates. Investigation using a specific assay for methylglyoxal. Eur. J. Biochem. 1993, 212, 101-105. [CrossRef] [PubMed]

2. Schalkwijk, C.G.; Stehouwer, C.D.A. Methylglyoxal, a Highly Reactive Dicarbonyl Compound, in Diabetes, Its Vascular Complications, and Other Age-Related Diseases. Physiol. Rev. 2020, 100, 407-461. [CrossRef] [PubMed]

3. Kang, Y.; Edwards, L.G.; Thornalley, P.J. Effect of methylglyoxal on human leukaemia 60 cell growth: Modification of DNA G1 growth arrest and induction of apoptosis. Leuk. Res. 1996, 20, 397-405. [CrossRef]

4. Seo, K.; Ki, S.H.; Shin, S.M. Methylglyoxal induces mitochondrial dysfunction and cell death in liver. Toxicol. Res. 2014, 30, 193-198. [CrossRef] [PubMed]

5. Baig, M.H.; Jan, A.T.; Rabbani, G.; Ahmad, K.; Ashraf, J.M.; Kim, T.; Min, H.S.; Lee, Y.H.; Cho, W.K.; Ma, J.Y.; et al. Methylglyoxal and Advanced Glycation End products: Insight of the regulatory machinery affecting the myogenic program and of its modulation by natural compounds. Sci. Rep. 2017, 7, 5916. [CrossRef]

6. Gkogkolou, P.; Bohm, M. Advanced glycation end products: Key players in skin aging? Dermatoendocrinology 2012, 4, 259-270. [CrossRef] [PubMed]

7. Rabbani, N.; Thornalley, P.J. Dicarbonyl proteome and genome damage in metabolic and vascular disease. Biochem. Soc. Trans. 2014, 42, 425-432. [CrossRef]

8. De Bari, L.; Atlante, A.; Armeni, T.; Kalapos, M.P. Synthesis and metabolism of methylglyoxal, S-D-lactoylglutathione and D-lactate in cancer and Alzheimer's disease. Exploring the crossroad of eternal youth and premature aging. Ageing Res. Rev. 2019, 53, 100915. [CrossRef]

9. Maessen, D.E.; Stehouwer, C.D.; Schalkwijk, C.G. The role of methylglyoxal and the glyoxalase system in diabetes and other age-related diseases. Clin. Sci. 2015, 128, 839-861. [CrossRef]

10. Nigro, C.; Leone, A.; Raciti, G.A.; Longo, M.; Mirra, P.; Formisano, P.; Beguinot, F.; Miele, C. Methylglyoxal-Glyoxalase 1 Balance: The Root of Vascular Damage. Int. J. Mol. Sci. 2017, 18, 188. [CrossRef]

11. Silva, M.S.; Gomes, R.A.; Ferreira, A.E.N.; Freire, A.P.; Cordeiro, C. The glyoxalase pathway: The first hundred years... and beyond. Biochem. J. 2013, 453, 1-15. [CrossRef] [PubMed]

12. Galeazzi, R.; Laudadio, E.; Falconi, E.; Massaccesi, L.; Ercolani, L.; Mobbili, G.; Minnelli, C.; Scire, A.; Cianfruglia, L.; Armeni, T. Protein-protein interactions of human glyoxalase II: Findings of a reliable docking protocol. Org. Biomol. Chem. 2018, 16, 5167-5177. [CrossRef]

13. Volpe, C.M.O.; Villar-Delfino, P.H.; Dos Anjos, P.M.F.; Nogueira-Machado, J.A. Cellular death, reactive oxygen species (ROS) and diabetic complications. Cell Death Dis. 2018, 9, 119. [CrossRef]

14. Nigro, C.; Leone, A.; Fiory, F.; Prevenzano, I.; Nicolo, A.; Mirra, P.; Beguinot, F.; Miele, C. Dicarbonyl Stress at the Crossroads of Healthy and Unhealthy Aging. Cells 2019, 8, 749. [CrossRef]

15. McLellan, A.C.; Thornalley, P.J.; Benn, J.; Sonksen, P.H. Glyoxalase system in clinical diabetes mellitus and correlation with diabetic complications. Clin. Sci. 1994, 87, 21-29. [CrossRef]

16. Moraru, A.; Wiederstein, J.; Pfaff, D.; Fleming, T.; Miller, A.K.; Nawroth, P.; Teleman, A.A. Elevated Levels of the Reactive Metabolite Methylglyoxal Recapitulate Progression of Type 2 Diabetes. Cell Metab. 2018, 27, 926-934. [CrossRef] [PubMed]

17. Jo-Watanabe, A.; Ohse, T.; Nishimatsu, H.; Takahashi, M.; Ikeda, Y.; Wada, T.; Shirakawa, J.; Nagai, R.; Miyata, T.; Nagano, T.; et al. Glyoxalase I reduces glycative and oxidative stress and prevents age-related endothelial dysfunction through modulation of endothelial nitric oxide synthase phosphorylation. Aging Cell 2014, 13, 519-528. [CrossRef] [PubMed]

18. Cianfruglia, L.; Perrelli, A.; Fornelli, C.; Magini, A.; Gorbi, S.; Salzano, A.M.; Antognelli, C.; Retta, F.; Benedetti, V.; Cassoni, P.; et al. KRIT1 Loss-Of-Function Associated with Cerebral Cavernous Malformation Disease Leads to Enhanced S-Glutathionylation of Distinct Structural and Regulatory Proteins. Antioxidants 2019, 8, 27. [CrossRef] [PubMed]

19. Antognelli, C.; Perrelli, A.; Armeni, T.; Nicola Talesa, V.; Retta, S.F. Dicarbonyl Stress and S-Glutathionylation in Cerebrovascular Diseases: A Focus on Cerebral Cavernous Malformations. Antioxidants 2020, 9, 124. [CrossRef] 
20. Morresi, C.; Cianfruglia, L.; Sartini, D.; Cecati, M.; Fumarola, S.; Emanuelli, M.; Armeni, T.; Ferretti, G.; Bacchetti, T. Effect of High Glucose-Induced Oxidative Stress on Paraoxonase 2 Expression and Activity in Caco-2 Cells. Cells 2019, 8, 1616. [CrossRef]

21. Sambuy, Y.; De Angelis, I.; Ranaldi, G.; Scarino, M.L.; Stammati, A.; Zucco, F. The Caco-2 cell line as a model of the intestinal barrier: Influence of cell and culture-related factors on Caco-2 cell functional characteristics. Cell Biol. Toxicol. 2005, 21, 1-26. [CrossRef] [PubMed]

22. Lea, T. Caco-2 Cell Line. In The Impact of Food Bioactives on Health: In Vitro and Ex Vivo models; Verhoeckx, K., Cotter, P., Lopez-Exposito, I., Kleiveland, C., Lea, T., Mackie, A., Requena, T., Swiatecka, D., Wichers, H., Eds.; Springer: Cham, Switzerland, 2015; pp. 103-111. [CrossRef]

23. Aw, T.Y. Molecular and cellular responses to oxidative stress and changes in oxidation-reduction imbalance in the intestine. Am. J. Clin. Nutr. 1999, 70, 557-565. [CrossRef] [PubMed]

24. Hussain, T.; Tan, B.; Yin, Y.; Blachier, F.; Tossou, M.C.; Rahu, N. Oxidative Stress and Inflammation: What Polyphenols Can Do for Us? Oxid. Med. Cell Longev. 2016, 2016, 7432797. [CrossRef]

25. Avila, F.; Theoduloz, C.; Lopez-Alarcon, C.; Dorta, E.; Schmeda-Hirschmann, G. Cytoprotective Mechanisms Mediated by Polyphenols from Chilean Native Berries against Free Radical-Induced Damage on AGS Cells. Oxid. Med. Cell Longev. 2017, 2017, 9808520. [CrossRef] [PubMed]

26. Tresserra-Rimbau, A.; Rimm, E.B.; Medina-Remon, A.; Martinez-Gonzalez, M.A.; Lopez-Sabater, M.C.; Covas, M.I.; Corella, D.; Salas-Salvado, J.; Gomez-Gracia, E.; Lapetra, J.; et al. Polyphenol intake and mortality risk: A re-analysis of the PREDIMED trial. BMC Med. 2014, 12, 77. [CrossRef] [PubMed]

27. Ferretti, G.T.I.; Bacchetti, T. Apple as a Source of Dietary Phytonutrients: Bioavailability and Evidence of Protective Effects against Human Cardiovascular Disease. Food Nutr. Sci. 2014, 5, 1234-1246. [CrossRef]

28. Yeh, W.J.; Hsia, S.M.; Lee, W.H.; Wu, C.H. Polyphenols with antiglycation activity and mechanisms of action: A review of recent findings. J. Food Drug Anal. 2017, 25, 84-92. [CrossRef]

29. Gu, C.; Howell, K.; Dunshea, F.R.; Suleria, H.A.R. LC-ESI-QTOF/MS Characterisation of Phenolic Acids and Flavonoids in Polyphenol-Rich Fruits and Vegetables and Their Potential Antioxidant Activities. Antioxidants 2019, 8, 405. [CrossRef]

30. Morresi, C.; Cianfruglia, L.; Armeni, T.; Mancini, F.; Tenore, G.C.; D’Urso, E.; Micheletti, A.; Ferretti, G.; Bacchetti, T. Polyphenolic compounds and nutraceutical properties of old and new apple cultivars. J. Food Biochem. 2018, 42, e12641. [CrossRef]

31. Saeidi, I.; Hadjmohammadi, M.R.; Peyrovi, M.; Iranshahi, M.; Barfi, B.; Babaei, A.B.; Dust, A.M. HPLC determination of hesperidin, diosmin and eriocitrin in Iranian lime juice using polyamide as an adsorbent for solid phase extraction. J. Pharm. Biomed. Anal. 2011, 56, 419-422. [CrossRef]

32. Singleton, V.L.; Orthofer, R.; Lamuela-Raventós, R.M. Analysis of total phenols and other oxidation substrates and antioxidants by means of Folin--Ciocalteu reagent. Methods Enzimol. 1999, 299, 152-178. [CrossRef]

33. Graziani, G.; D’Argenio, G.; Tuccillo, C.; Loguercio, C.; Ritieni, A.; Morisco, F.; Del Vecchio Blanco, C.; Fogliano, V.; Romano, M. Apple polyphenol extracts prevent damage to human gastric epithelial cells in vitro and to rat gastric mucosa in vivo. Gut 2005, 54, 193-200. [CrossRef] [PubMed]

34. La Selva, M.; Beltramo, E.; Pagnozzi, F.; Bena, E.; Molinatti, P.A.; Molinatti, G.M.; Porta, M. Thiamine corrects delayed replication and decreases production of lactate and advanced glycation end-products in bovine retinal and human umbilical vein endothelial cells cultured under high glucose conditions. Diabetologia 1996, 39, 1263-1268. [CrossRef] [PubMed]

35. Linden, A.; Gulden, M.; Martin, H.J.; Maser, E.; Seibert, H. Peroxide-induced cell death and lipid peroxidation in C6 glioma cells. Toxicol. In Vitro 2008, 22, 1371-1376. [CrossRef] [PubMed]

36. Wan, H.X.; Liu, D.; Yu, X.Y.; Sun, H.Y.; Li, Y. A Caco-2 cell-based quantitative antioxidant activity assay for antioxidants. Food Chem. 2015, 175, 601-608. [CrossRef] [PubMed]

37. Brigelius, R.; Muckel, C.; Akerboom, T.P.; Sies, H. Identification and quantitation of glutathione in hepatic protein mixed disulfides and its relationship to glutathione disulfide. Biochem. Pharmacol. 1983, 32, 2529-2534. [CrossRef]

38. Arai, M.; Nihonmatsu-Kikuchi, N.; Itokawa, M.; Rabbani, N.; Thornalley, P.J. Measurement of glyoxalase activities. Biochem. Soc. Trans. 2014, 42, 491-494. [CrossRef]

39. Ercolani, L.; Scire, A.; Galeazzi, R.; Massaccesi, L.; Cianfruglia, L.; Amici, A.; Piva, F.; Urbanelli, L.; Emiliani, C.; Principato, G.; et al. A possible S-glutathionylation of specific proteins by glyoxalase II: An in vitro and in silico study. Cell Biochem. Funct. 2016, 34, 620-627. [CrossRef] 
40. Kawahito, S.; Kitahata, H.; Oshita, S. Problems associated with glucose toxicity: Role of hyperglycemia-induced oxidative stress. World J. Gastroenterol. 2009, 15, 4137-4142. [CrossRef] [PubMed]

41. Kaneto, H.; Fujii, J.; Myint, T.; Miyazawa, N.; Islam, K.N.; Kawasaki, Y.; Suzuki, K.; Nakamura, M.; Tatsumi, H.; Yamasaki, Y.; et al. Reducing sugars trigger oxidative modification and apoptosis in pancreatic beta-cells by provoking oxidative stress through the glycation reaction. Biochem. J. 1996, 320, 855-863. [CrossRef] [PubMed]

42. Ratliff, D.M.; Vander Jagt, D.J.; Eaton, R.P.; Vander Jagt, D.L. Increased levels of methylglyoxal-metabolizing enzymes in mononuclear and polymorphonuclear cells from insulin-dependent diabetic patients with diabetic complications: Aldose reductase, glyoxalase I, and glyoxalase II-a clinical research center study. J. Clin. Endocrinol. Metab. 1996, 81, 488-492. [CrossRef]

43. Staniszewska, M.M.; Nagaraj, R.H. Upregulation of glyoxalase I fails to normalize methylglyoxal levels: A possible mechanism for biochemical changes in diabetic mouse lenses. Mol. Cell Biochem. 2006, 288, 29-36. [CrossRef] [PubMed]

44. Atkins, T.W.; Thornally, P.J. Erythrocyte glyoxalase activity in genetically obese (ob/ob) and streptozotocin diabetic mice. Diabetes Res. 1989, 11, 125-129. [PubMed]

45. Uchino, E.; Fukushima, T.; Tsunoda, M.; Santa, T.; Imai, K. Determination of rat blood S-D-lactoylglutathione by a column-switching high-performance liquid chromatography with precolumn fluorescence derivatization with 4-fluoro-7-nitro-2,1,3-benzoxadiazole. Anal. Biochem. 2004, 330, 186-192. [CrossRef] [PubMed]

46. Barati, M.T.; Merchant, M.L.; Kain, A.B.; Jevans, A.W.; McLeish, K.R.; Klein, J.B. Proteomic analysis defines altered cellular redox pathways and advanced glycation end-product metabolism in glomeruli of $\mathrm{db} / \mathrm{db}$ diabetic mice. Am. J. Physiol. Renal Physiol. 2007, 293, F1157-F1165. [CrossRef] [PubMed]

47. Li, W.; Maloney, R.E.; Aw, T.Y. High glucose, glucose fluctuation and carbonyl stress enhance brain microvascular endothelial barrier dysfunction: Implications for diabetic cerebral microvasculature. Redox Biol. 2015, 5, 80-90. [CrossRef]

48. Scirè, A.; Tanfani, F.; Saccucci, F.; Bertoli, E.; Principato, G. Specific interaction of cytosolic and mitochondrial glyoxalase II with acidic phospholipids in form of liposomes results in the inhibition of the cytosolic enzyme only. Proteins 2000, 1,33-39. [CrossRef]

49. Armeni, T.; Cianfruglia, L.; Piva, F.; Urbanelli, L.; Caniglia, M.; Pugnaloni, A.; Principato, G. S-D-Lactoylglutathione can be an alternative supply of mitochondrial glutathione. Free Radic. Biol. Med. 2014, 67, 451-459. [CrossRef]

50. Laudadio, E.; Cedraro, N.; Mangiaterra, G.; Citterio, B.; Mobbili, G.; Minnelli, C.; Bizzaro, D.; Biavasco, F.; Galeazzi, R. Natural Alkaloid Berberine Activity against Pseudomonas aeruginosa MexXY-Mediated Aminoglycoside Resistance: In Silico and in Vitro studies. J. Nat. Prod. 2019, 26, 1935-1944. [CrossRef]

51. Sadowska-Bartosz, I.; Galiniak, S.; Bartosz, G. Polyphenols protect against protein glycoxidation. Free Radic. Biol. Med. 2014, 75 (Suppl. S1), S47. [CrossRef]

52. Ferretti, G.; Neri, D.; Bacchetti, T. Effect of Italian Sour Cherry (Prunus cerasus L.) on the Formation of Advanced Glycation End Products and Lipid Peroxidation. Food Nutr. Sci. 2014, 5, 1568-1576. [CrossRef]

53. Lo, C.Y.; Hsiao, W.T.; Chen, X.Y. Efficiency of trapping methylglyoxal by phenols and phenolic acids. J. Food Sci. 2011, 76, H90-H96. [CrossRef] [PubMed]

54. Li, X.; Zheng, T.; Sang, S.; Lv, L. Quercetin inhibits advanced glycation end product formation by trapping methylglyoxal and glyoxal. J. Agric. Food Chem. 2014, 62, 12152-12158. [CrossRef]

55. Shao, X.; Bai, N.; He, K.; Ho, C.T.; Yang, C.S.; Sang, S. Apple polyphenols, phloretin and phloridzin: New trapping agents of reactive dicarbonyl species. Chem. Res. Toxicol. 2008, 21, 2042-2050. [CrossRef]

56. Frandsen, J.; Narayanasamy, P. Flavonoid Enhances the Glyoxalase Pathway in Cerebellar Neurons to Retain Cellular Functions. Sci. Rep. 2017, 7, 5126. [CrossRef]

57. Santel, T.; Pflug, G.; Hemdan, N.Y.; Schafer, A.; Hollenbach, M.; Buchold, M.; Hintersdorf, A.; Lindner, I.; Otto, A.; Bigl, M.; et al. Curcumin inhibits glyoxalase 1: A possible link to its anti-inflammatory and anti-tumor activity. PLoS ONE 2008, 3, e3508. [CrossRef]

58. Douglas, K.T.; Gohel, D.I.; Nadvi, I.N.; Quilter, A.J.; Seddon, A.P. Partial transition-state inhibitors of glyoxalase I from human erythrocytes, yeast and rat liver. Biochim. Biophys. Acta 1985, 829, 109-118. [CrossRef] 
59. Douglas, K.T.; Quilter, A.J.; Shinkai, S.; Ueda, K. Trapping of reactive intermediates in enzymology. Exogenous flavin reduction during catalytic turnover of substrate by glyoxalase I. Biochim. Biophys. Acta 1985, 829, 119-126. [CrossRef]

60. Myhrstad, M.C.; Carlsen, H.; Nordstrom, O.; Blomhoff, R.; Moskaug, J.O. Flavonoids increase the intracellular glutathione level by transactivation of the gamma-glutamylcysteine synthetase catalytical subunit promoter. Free Radic. Biol. Med. 2002, 32, 386-393. [CrossRef]

61. Scire, A.; Cianfruglia, L.; Minnelli, C.; Bartolini, D.; Torquato, P.; Principato, G.; Galli, F.; Armeni, T. Glutathione compartmentalization and its role in glutathionylation and other regulatory processes of cellular pathways. Biofactors 2019, 45, 152-168. [CrossRef] [PubMed]

62. Cianfruglia, L.; Minnelli, C.; Laudadio, E.; Scirè, A.; Armeni, T. Side Effects of Curcumin: Epigenetic and Antiproliferative Implications for Normal Dermal Fibroblast and Breast Cancer Cells. Antioxidants 2019, 9, 382. [CrossRef] [PubMed]

63. Takasawa, R.; Takahashi, S.; Saeki, K.; Sunaga, S.; Yoshimori, A.; Tanuma, S. Structure-activity relationship of human GLO I inhibitory natural flavonoids and their growth inhibitory effects. Bioorg. Med. Chem. 2008, 16, 3969-3975. [CrossRef] [PubMed]

64. Eberhardt, M.V.; Lee, C.Y.; Liu, R.H. Antioxidant activity of fresh apples. Nature 2000, 405, 903-904. [CrossRef] [PubMed]

65. Halliwell, B.; Rafter, J.; Jenner, A. Health promotion by flavonoids, tocopherols, tocotrienols, and other phenols: Direct or indirect effects? Antioxidant or not? Am. J. Clin. Nutr. 2005, 81, 268S-276S. [CrossRef]

66. Scalbert, A.; Deprez, S.; Mila, I.; Albrecht, A.M.; Huneau, J.F.; Rabot, S. Proanthocyanidins and human health: Systemic effects and local effects in the gut. Biofactors 2000, 13, 115-120. [CrossRef]

67. Aragonès, G.D.F.; Del Rio, D.; Menac, P. The importance of studying cell metabolism when testing the bioactivity of phenolic compounds. Trends Food Sci. Technol. 2017, 69, 230-242. [CrossRef]

68. Serreli, G.D.M. In vivo formed metabolites of polyphenols and their biological efficacy. Food Funct. 2019, 10, 6999-7021. [CrossRef]

Publisher's Note: MDPI stays neutral with regard to jurisdictional claims in published maps and institutional affiliations.

(C) 2020 by the authors. Licensee MDPI, Basel, Switzerland. This article is an open access article distributed under the terms and conditions of the Creative Commons Attribution (CC BY) license (http://creativecommons.org/licenses/by/4.0/). 